\title{
REDUÇÃO DE MINÉRIO LATERÍTICO A PARTIR DA UTILIZAÇÃO DE MISTURA DE COMBUSTÍVEIS SÓLIDOS E LÍQUIDOS*
}

\section{Resumo}

Marcos Campos Silveira Thiago Figueiredo Cruz $^{2}$ Paulo André Cavalcante José Eduardo de Souza José Eloi Nogueira ${ }^{5}$ Clauber Geraldo Gomes ${ }^{6}$ Marcos Luis Aires Neliton Dias Vieira ${ }^{8}$ Jaderson Francisco dos Santos ${ }^{9}$ Rodrigo Alberto Moreira Gomes ${ }^{10}$

A Unidade Niquelândia da Votorantim Metais possui 9 fornos multi andares usados para a redução de minérios lateríticos com o uso de monóxido de carbono e hidrogênio como agentes redutores. Cada forno possui 10 câmaras de combustão para geração destes gases que trabalham em contra-corrente com o minério alimentado pelo topo do forno. Já utilizado como combustível óleo A2 incorporado ao minério bem como sua combustão em câmaras. O trabalho consiste na substituição do óleo por uma emulsão de combustíveis líquidos e sólidos a fim de flexibilizar a matriz energética e promover redução do cash cost sem queda na eficiência operacional. A utilização industrial da emulsão teve início em 2006 através da sua incorporação ao minério alimentado na proporção de $19 \%$ de coque de petróleo e $81 \%$ de óleo A2 em poder calorífico e em 2014 esta mistura alcançou a proporção de 39\% de coque e $61 \%$ de óleo A1. Em paralelo e após testes de combustão em planta piloto, foram realizados testes industriais de queima também nas câmaras de combustão em dezembro de 2012. Com o bom desempenho, em dezembro de 2013, 14 das 90 câmaras já estavam nesta condição com previsão de 20 câmaras até junho de 2014 otimizando a capacidade da estação de óleo+coque. Com isto a substituição (\%) global dos fornos em poder calorífico avançou de 6,38\% em 2011 para 16,12\% em 2014 acumulados até abril. Com uma nova estação existe a possibilidade de operar 90 câmaras nesta condição e chegar a um valor de $39 \%$ de substituição global.

Palavras-chave: Combustão; Cash cost; Poder calorífico; Emulsão.

\section{Abstract}

\section{REDUCTION OF LATERITIC ORES USING A MIXTURE OF SOLID AND LIQUID FUELS}

Niquelândia unit of Votorantim Metais has 9 multi-storey ovens used for the reduction of lateritic ores with the use of carbon monoxide and hydrogen as reducing agents. Each furnace has 10 combustion chambers for generation of these gases work in counter-current with the ore fed from the top of the furnace. It is already used as fuel oil A2 incorporated into the ore and its combustion chambers. The work involves replacing the oil with an emulsion of liquid and solid fuels with the aim of easing the energy matrix promoting reduction in cash cost no drop in operational efficiency. Use the emulsion began in 2011 through its incorporation into the ore fed in the proportion of $19 \%$ of petroleum coke and $81 \%$ oil calorific value in A2 in 2014 and this mixture reached the proportion of $39 \%$ coke and $61 \%$ of A1 oil. In parallel to this breakthrough burning this mixture tests were also initiated in the combustion chambers in December 2012. With its success, in December 201314 of 90 chambers were already in this condition with forecast of 20 cameras to June 2014 reaching the maximum capacity of oil + coke station. Through these steps to replace (\%) Overall ovens in calorific value increased from $6.38 \%$ in 2011 to $16.12 \%$ in 2014 retained until April. With a new season there is the possibility to operate 90 cameras in this condition and reach a value of $39 \%$ of total replacement.

Keywords: Combustion; Cash cost; Calorific value; Emulsion.

1 Engenheiro Metalúrgico, Pós Graduação em Gestão Empresarial, Gerente, Via Seca, Votorantim Metais, Niquelândia, GO, Brasil.

2 Engenheiro Metalúrgico, cursando Pós Graduação (MBA) em Gerenciamento de Projetos, Engenheiro de Operações, Via Seca, Votorantim Metais, Niquelândia, GO, Brasil.

3 Engenheiro Metalúrgico, Pós Graduação em Polímeros e Elastômeros e MBA em Engenharia de Produção, Consultor de Processos, Via Seca, Votorantim Metais, Niquelândia, GO, Brasil.

4 Técnico em Metalurgia, Técnico Sênior de Operações, Via Seca, Votorantim Metais, Niquelândia, GO, Brasil.

5 Técnico em Metalurgia, Consultor de Operações, Via Seca, Nogueira Consultoria, Niquelândia, GO, Brasil.

6 Graduação em Ciências Contábeis e Técnico em Metalurgia, Pós Graduação (MBA) em Gerenciamento de Projetos, Assessor de Eng. Mecânica, Eng. de Manutenção, Votorantim Metais, Niquelândia, GO, Brasil.

7 Técnico em Mecânica, Supervisor de Manutenção Mecânica, Eng. de Manutenção, Votorantim Metais, Niquelândia, GO, Brasil.

8 Técnico em Eletrônica, Supervisor de Instrumentação, Eng. de Manutenção, Votorantim Metais, Niquelândia, GO, Brasil.

9 Eng. Mecânico, Eng. de Manutenção Mecânica, Votorantim Metais, Niquelândia, GO, Brasil.

10 Engenheiro Mecânica, Térmica, Mestre em Tecnologia Mineral, Gerente Corporativo de Tecnologia em Energia e Planejamento Estratégico, Diretoria de Tecnologia, Votorantim Metais, Belo Horizonte, MG, Brasil.

\footnotetext{
* Contribuição técnica ao $35^{\circ}$ Seminário de Balanços Energéticos Globais e Utilidades e $29^{\circ}$ Encontro de Produtores e Consumidores de Gases Industriais, 13 a 15 de agosto de 2014, São Paulo, SP, Brasil.
} 


\section{INTRODUÇÃO}

\subsection{A Unidade}

As instalações da Votorantim Metais se encontram a $280 \mathrm{~km}$ de Brasília e a $350 \mathrm{~km}$ de Goiânia. A Usina Macedo dista, aproximadamente, $15 \mathrm{~km}$ da cidade de Niquelândia, e o acesso é pela via estadual GO-535. As mineralizações de níquel laterítico, em questão, foram descobertas em 1929. Estes depósitos estão localizados no Complexo Máfico-Ultramáfico de São José do Tocantins, também denominado Complexo Máfico-Ultramáfico de Niquelândia, norte do estado de Goiás. As jazidas de níquel laterítico da Votorantim Metais (VM)-Niquelândia estão localizadas na zona ultramáfica do Complexo e encontram-se, de forma geral, acima de $1.050 \mathrm{~m}$ de altitude, orientação aproximada N15E e se estendem ao longo de 17 $\mathrm{km}$ numa faixa de $2 \mathrm{~km}$. A unidade possui 918 funcionários diretos e atualmente com 990 terceirizados, no período de lavra o número de funcionários terceirizados pode chegar a 1800. A Votorantim Metais Niquelandia é detentora dos direitos minerais caracterizados por manifesto de mina no maciço de Niquelândia. É uma empresa constituída com fins de extração e beneficiamento de Níquel. Acompanhando a filosofia de todo o Grupo Votorantim, desenvolve suas atividades com preocupação especial pelo meio ambiente, segurança e saúde, executando o processo de produção de acordo com os princípios do desenvolvimento sustentável.

A reserva atual lavrável da Votorantim Metais é de 41,7 milhões de toneladas com teores médios de $1,0 \%$ de $\mathrm{Ni}, 0,119 \% \mathrm{Co}$, e $0,154 \% \mathrm{Cu}$. O minério é classificado em dois tipos - o minério silicatado e o oxidado. $\mathrm{O}$ minério silicatado apresenta teores médios de $2,6 \% \mathrm{Ni}, 15 \% \mathrm{Fe}, 41 \% \mathrm{SiO} 2,0,14 \% \mathrm{Co}$ e $0,17 \% \mathrm{Cu}$, enquanto que no oxidado tem-se teores médios de $0,9 \% \mathrm{Ni}$ e $40 \% \mathrm{Fe}$. A unidade do negócio níquel em Niquelândia utiliza o processo Caron para tratamento do minério laterítico. Este processo envolve etapas de britagem, moagem, secagem, redução e lixiviação amoniacal do minério reduzido. A parte Pirometalurgica do processo é extremamente dependente de combustíveis fósseis. A redução é uma etapa crítica do processo e tem como objetivo reduzir seletivamente o níquel e o cobalto para o estado metálico. Atualmente o consumo de óleo $1 \mathrm{~A}$ nos fornos corresponde a $86,7 \%$ do consumo total da planta. Este fato faz com que a unidade de Niquelândia da Votorantim Metais Níquel busque reduzir os custos da sua matriz energética substituindo o óleo combustível 1A por outros combustíveis de menor custo - como é o caso do coque de petróleo. O custo CIF do coque em Niquelândia é da ordem da metade do custo CIF do óleo combustível por unidade de energia liberada.

\subsection{Macro Fluxo do Processo}

A figura 1 mostra uma visão macro do nosso processo de produção, sendo a área de atuação desse projeto, os fornos de Redução.

\footnotetext{
* Contribuição técnica ao $35^{\circ}$ Seminário de Balanços Energéticos Globais e Utilidades e $29^{\circ}$ Encontro de Produtores e Consumidores de Gases Industriais, 13 a 15 de agosto de 2014, São Paulo, SP, Brasil.
} 


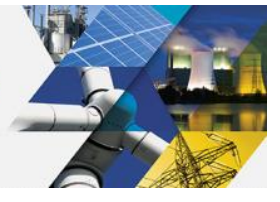

Metalurgia

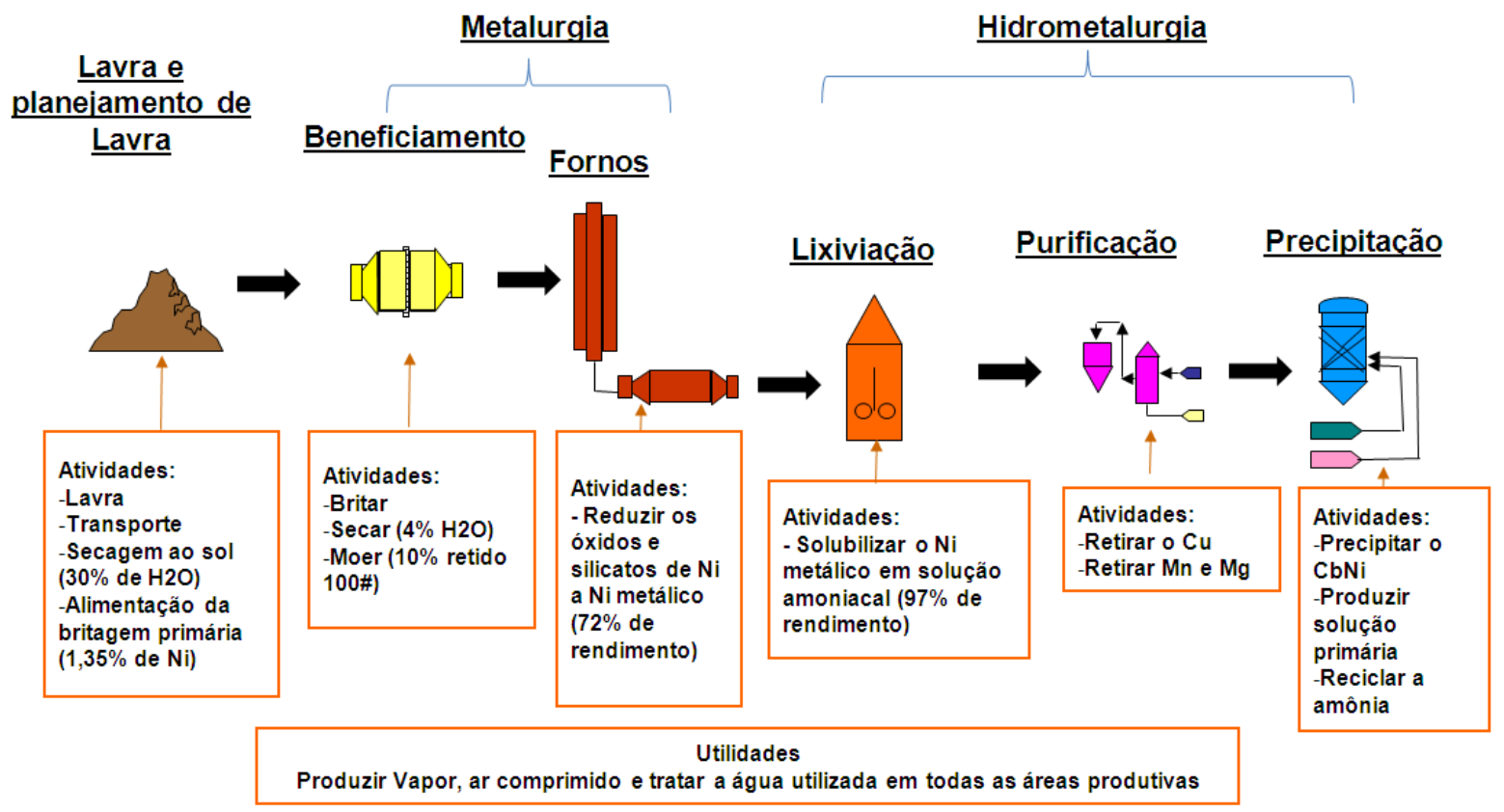

Figura 1: Macro fluxo do processo

\subsection{Fornos de Redução}

A função desta etapa do processo é reduzir os metais presentes para o seu estado fundamental obtendo o máximo de metalização nos fornos. O setor de Redução de Minério em Niquelândia é composto por nove fornos multi andares modelo Nichols Hereshoff (figura 2) usados para a redução minérios lateríticos, com o emprego de monóxido de carbono (CO) e hidrogênio $\left(\mathrm{H}_{2}\right)$ como agentes redutores. Estes gases criam condições fortemente redutoras e são gerados a partir da queima de óleo combustível $1 \mathrm{~A}$ com quantidades subestequiométricas de ar. Os queimadores usados nos fornos de redução são modelos Hauck. Para suprir a capacidade térmica total dos fornos uma parcela de aproximadamente $2 \%$ em relação a massa alimentada é incorporada ao minério na sua alimentação no topo do forno, que também ajuda a reduzir o consumo de óleo combustível. Os fornos tem capacidade nominal de alimentação de minério seco e moído de 32,50 t/h cada. Este é proveniente da etapa anterior de secagem e moagem e possui como especificações de processo umidade entre 3 e $5 \%$ e granulometria entre 6 a $8 \%$ retido na peneira de 100 mesh.

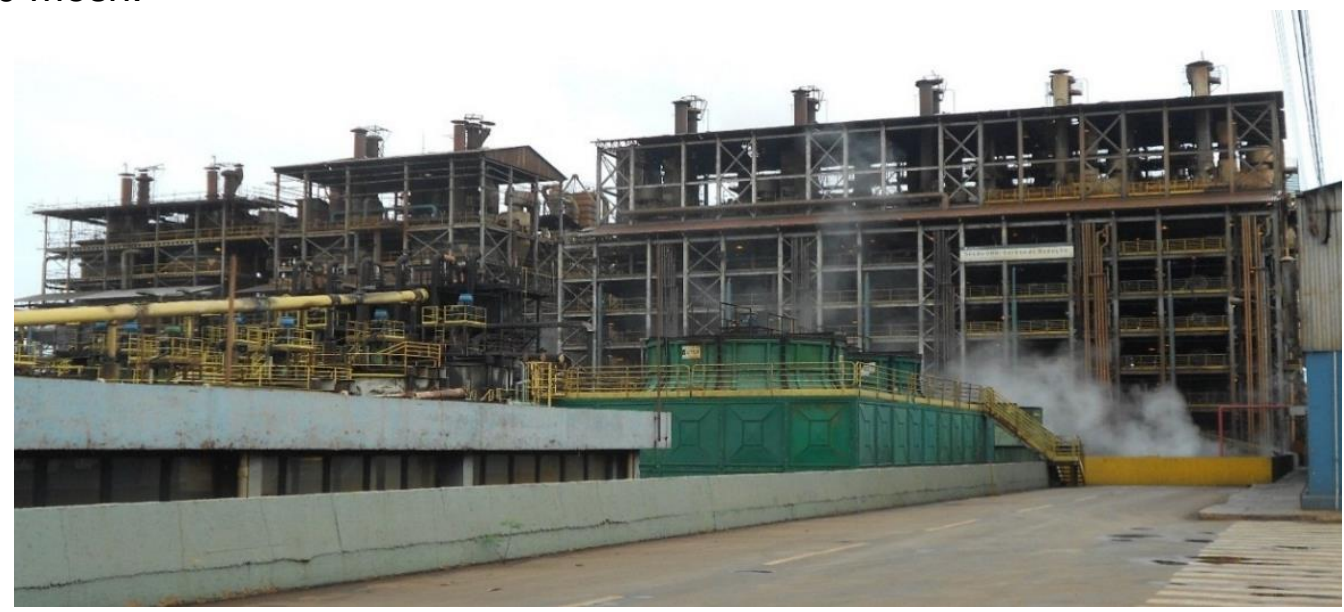

Figura 2 - Vista parcial dos fornos de redução

* Contribuição técnica ao $35^{\circ}$ Seminário de Balanços Energéticos Globais e Utilidades e $29^{\circ}$ Encontro de Produtores e Consumidores de Gases Industriais, 13 a 15 de agosto de 2014, São Paulo, SP, Brasil. 


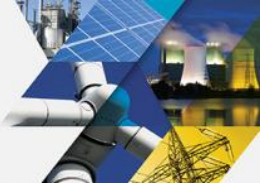

A reação química desejada nos fornos é a de redução do minério do estado sólido por meio de um gás redutor, formando o metal em seu estado fundamental e gases estáveis em seu máximo de oxidação como a água e o dióxido de carbono (CO2). As reações abaixo representam as principais reações de redução dos fornos.

$\begin{array}{lllll}\mathrm{NiO}(\mathrm{s}) & + & \mathrm{CO}(\mathrm{g}) \Leftrightarrow & \mathrm{Ni}(\mathrm{s})+ & \mathrm{CO} 2(\mathrm{~g}) \\ \mathrm{NiO}(\mathrm{s}) & + & \mathrm{H} 2(\mathrm{~g}) \Leftrightarrow & \mathrm{Ni}(\mathrm{s})+ & \mathrm{H} 2 \mathrm{O}(\mathrm{g}) \\ \mathrm{CoO}(\mathrm{s}) & + & \mathrm{CO}(\mathrm{g}) \Leftrightarrow & \mathrm{Co}(\mathrm{s})+ & \mathrm{CO} 2(\mathrm{~g}) \\ \mathrm{CoO}(\mathrm{s}) & + & \mathrm{H} 2(\mathrm{~g}) \Leftrightarrow & \mathrm{Co}(\mathrm{s})+ & \mathrm{H} 2 \mathrm{O}(\mathrm{g})\end{array}$

A geração do gás redutor é feita através da combustão de óleo combustível $1 \mathrm{~A}$ em câmaras de combustão. Cada forno possui 10 câmaras dispostas da seguinte forma: duas câmaras diametralmente opostas para cada andar impar entre os andares 7 e 15 do forno. A queima de óleos combustíveis de baixo teor de enxofre puro em bicos queimadores com atomização / pulverização mecânica ou por injeção de vapor ou ar é de domínio público sendo utilizada em vários setores da indústria na geração de energia. Mesmo a queima com insuficiência de ar, relação subestequiométrica é utilizada na unidade de Niquelândia há mais de 20 anos. A inovação do projeto em questão consiste em substituir uma parcela do óleo combustível 1A por uma parcela de coque moído formando uma emulsão com atualmente $39 \%$ de coque em energia que será consumida nos queimadores das câmaras de combustão dos fornos bem como sua incorporação ao minério no topo do forno. Não se tem conhecimento desta prática em outra indústria tornando esse projeto de mistura de combustíveis para redução de minérios lateríticos um diferencial de tecnologia e inovação.

\section{MATERIAIS E MÉTODOS}

\subsection{Planejamento do Teste de Óleo+Coque na Rosca de Alimentação dos Fornos}

O projeto foi idealizado a partir da necessidade de reduzir custos, logo a redução de cash cost foi o principal motivador para a execução do projeto que será descrito a seguir. Em meados de 2004, após todo um levantamento bibliográfico e uma sequencia de testes positivos em fornos de bancada, o projeto foi selecionado no banco de projetos da Votorantim Metais via CAPEX objetivando realizar a mistura de óleo+coque na proporção de $30 \%$ de coque em energia. O processo de preparo da emulsão inicia através da dosagem do combustível líquido (A1/A2) a uma temperatura aproximada de $140^{\circ} \mathrm{C}$ em um tanque de mistura que comporta $30 \mathrm{~m}^{3}$ de volume e possui agitador para promover a homogeneização. Após a dosagem do óleo, é feita a dosagem do coque conforme cálculo de substituição (30\%) em poder calorífico. Esta mistura passa por uma recirculação em um trocador de calor com intuito de aumentar temperatura afim de chegar na viscosidade de trabalho. A emulsão é então transferida para o tanque de dosagem que possui características similares ao anterior e esta é incorporada ao minério alimentado pelo topo do forno.

\subsection{Execução do Teste de Óleo+Coque na Rosca de Alimentação dos Fornos}

O projeto teve início em 2006 com um ramp up de substituição de óleo por coque que chegou $19 \%$ em 2008. Contudo, ocorreram problemas operacionais como entupimentos e quebra de equipamentos, gerando muitas variações de processo, o que nos obrigou a paralisar a utilização durante o ano de 2009 com retorno em meados de 2010. A partir de dezembro de 2011 foi possível retornar a operação com

* Contribuição técnica ao $35^{\circ}$ Seminário de Balanços Energéticos Globais e Utilidades e $29^{\circ}$ Encontro de Produtores e Consumidores de Gases Industriais, 13 a 15 de agosto de 2014, São Paulo, SP, Brasil. 
uma substituição de $15 \%$ que perdurou até julho de 2011 . Durante este período houve um grande aprendizado por parte da equipe e através de reuniões e discussões foram levantadas hipóteses do uso de um aditivo para melhorar a eficiência da mistura através da redução da viscosidade da mesma. Com a parceria da empresa TECCOM foi possível melhorar o processo de mistura e em julho de 2011 foi alcançado o resultado de $24 \%$ de substituição. O processo ainda passa por melhoria contínua na qual engloba a utilização de metodologia 6 Sigma e em março de 2012 foi alcançado o resultado de $30 \%$ de substituição. Atualmente o projeto já superou o planejado com a marca de 39\% em 2014.

\subsection{Planejamento do Teste de Óleo+Coque nas Câmaras de Combustão}

Por ser um combustível sólido existiam muitas dúvidas se era possível fazer a geração de gás redutor a partir da combustão incompleta do coque, nas câmaras de combustão dos fornos de Niquelândia. Assim, seguindo a metodologia cientifica e as boas práticas de inovação, foi decidido em 2007 que seria construída uma planta piloto de combustão onde faríamos todos os testes necessários para confirmar a hipótese que era possível gaseificar a mistura de óleo+coque. Foram realizados diversos testes, em parceria com IPT e Dynamis, com excelentes resultados para misturas com $25 \%$ de coque $75 \%$ de óleo. Contudo, verificaram-se problemas operacionais que poderiam inviabilizar a gaseificação industrial.

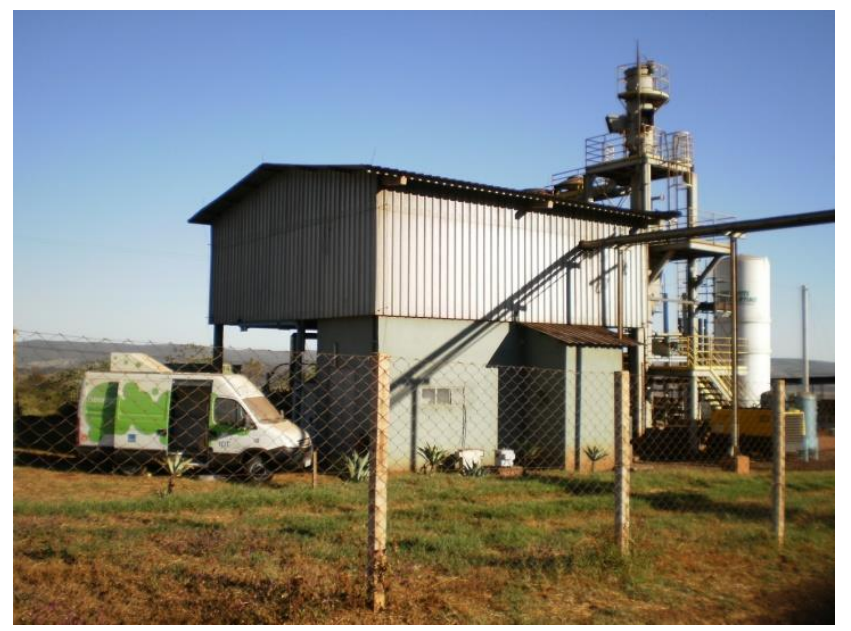

Figura 3. Planta piloto de combustão na VMN Niquelândia junto ao veiculo de monitoramento on-line de emissões do IPT.

Em 2012 após todo aprendizado e otimização operacional em relação à estação de mistura dos combustíveis, óleos A2/A1 e coque de petróleo, foi observado que esta emulsão havia alcançado características que possibilitavam a sua utilização também nas câmaras de combustão dos fornos. Como já dispúnhamos da estação de preparação de óleo+coque, surgiu a oportunidade do aproveitamento da capacidade ociosa da mesma. Assim, de dezembro de 2012 a abril de 2013 foram montadas duas estruturas para queima da emulsão nas câmaras 07I e 09I respectivamente, ambas pertencem ao forno I, utilizando também partes da planta piloto. Após levantamento de dados com base no teste com estas duas câmaras foi verificado que com pouco investimento conseguiríamos adaptar mais 10 câmaras do Forno $\mathrm{H}$ para a queima da emulsão, ou seja, teríamos 1 forno completo utilizando a mistura de óleo+coque sendo esta incorporada ao minério alimentado no topo do forno para

* Contribuição técnica ao $35^{\circ}$ Seminário de Balanços Energéticos Globais e Utilidades e $29^{\circ}$ Encontro de Produtores e Consumidores de Gases Industriais, 13 a 15 de agosto de 2014, São Paulo, SP, Brasil. 


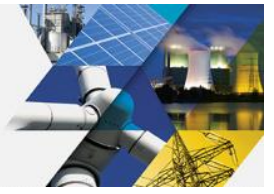

suprir a capacidade térmica total bem como utilizar como combustível das câmaras de combustão.

Tendo em vista a complexidade de se operar o forno que trabalha em condição redutora com $100 \%$ da carga térmica proveniente da mistura de combustíveis sólidos e líquidos, foi desenvolvido o seguinte modelo para gestão do projeto do forno $\mathrm{H}$ :

$>$ Definição do escopo do projeto (figura 4)

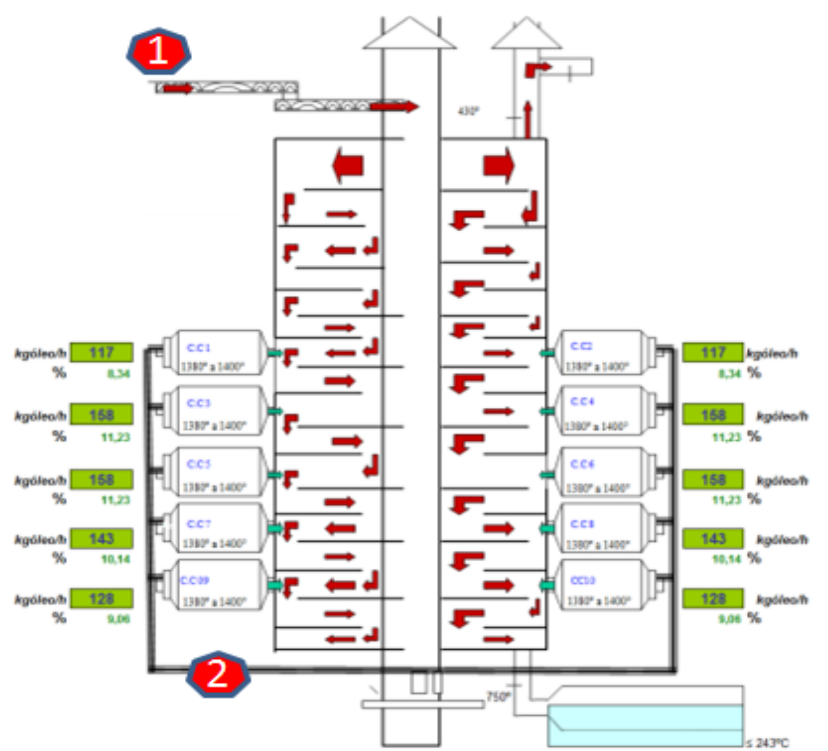

1 Injeção de emulsão de óleo+coque na alimentação dos fornos

2 Distribuição da emulsão para as câmaras de combustão dos fornos

O projeto foi implantado nas 10 câmaras do forno $\mathrm{H}$ e atualmente a mesma emulsão de óleotcoque que era incorporada ao minério (Ponto 1) está sendo queimada nas câmaras de combustão (Ponto 2).

Figura 4 - Fluxo simplificado do processo de queima de emulsão

> Elaboração de projeto executivo, por empresa parceira, com todos os desenhos técnicos para que a instalação fosse feita seguindo todas as normas de segurança.

$>$ Formação de uma equipe de manutenção exclusiva para montagem do sistema de transporte de emulsão, e instalação equipamentos de queima e controle da combustão.

$>$ Treinamento dos operadores envolvidos.

> Reuniões periódicas para análise e sugestões para a correção dos problemas surgidos.

Análise da sustentabilidade do projeto.

\subsection{Execução do Teste de Óleo+Coque nas Câmaras de Combustão}

Conforme planejamento já descrito, a estação de preparação da emulsão existente foi adaptada para enviar a emulsão aos queimadores das câmaras de combustão. Foram montadas tubulações com traço de vapor para transporte da emulsão, cavaletes com válvulas controladoras de vazão e transmissores de fluxos semelhantes e paralelos ao sistema de queima de óleo puro existente bem como adaptação dos bicos injetores. A figura 05 mostra uma câmara de combustão comum e uma câmara de combustão após sofrer a modificação. Praticamente só a parte de acessórios que sofreu alteração.

\footnotetext{
* Contribuição técnica ao $35^{\circ}$ Seminário de Balanços Energéticos Globais e Utilidades e $29^{\circ}$ Encontro de Produtores e Consumidores de Gases Industriais, 13 a 15 de agosto de 2014, São Paulo, SP, Brasil.
} 

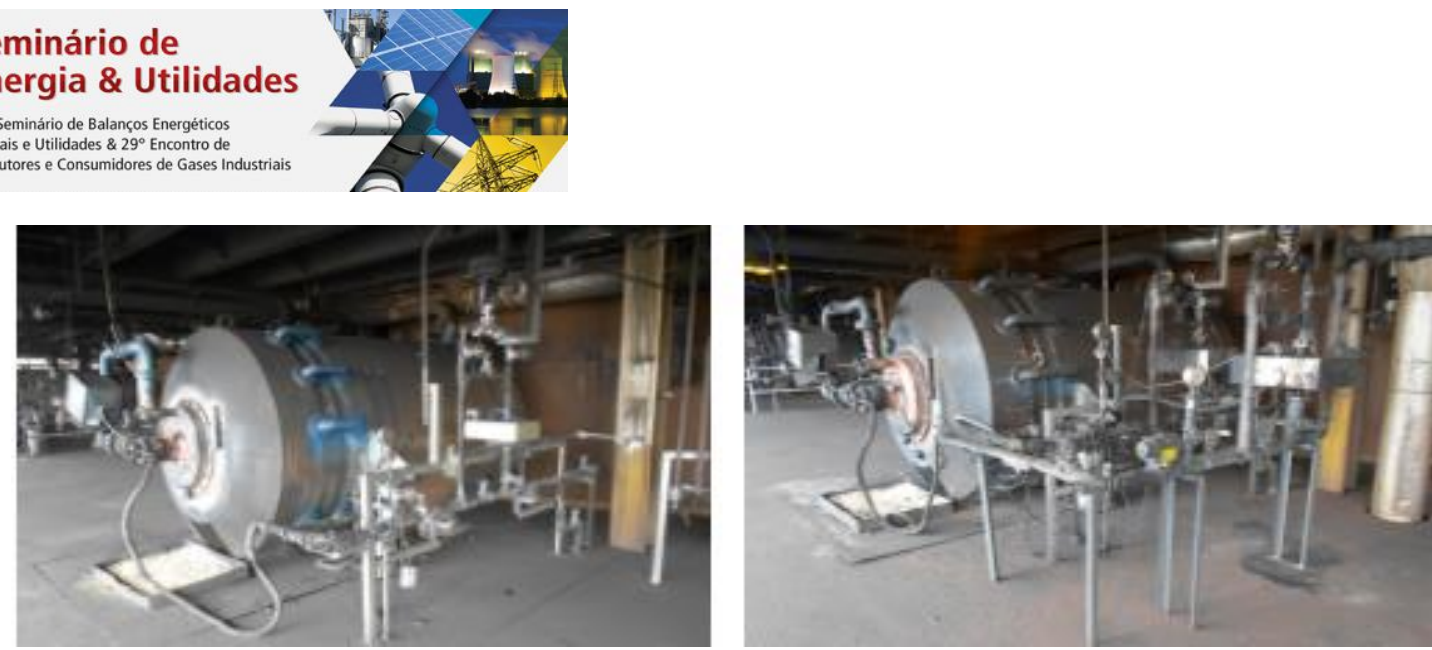

Figura 5 - Uma câmara de combustão sem adaptação e câmara 04 H adaptada para queimar emulsão

O Forno $\mathrm{H}$ iniciou a queima da emulsão em meados de agosto de 2013 e como todo projeto inovador, houve uma série de dificuldades em conseguir os resultados obtidos nas câmaras de teste do forno l. Dificuldades tais como variação muito forte na vazão de emulsão alimentada nos queimadores, entupimentos de bicos injetores, entre outros. Em reuniões entre manutenção e operação através da metodologia TOC - Teoria das Restrições, análises gráficas e utilizando a experiência e conhecimento dos membros da equipe, foi possível superar as dificuldades e, após um período de aprendizado e melhorias reiniciamos a operação em partes. Inicialmente foram acesas 4 câmaras e aos poucos às demais até atingirmos as 10 câmaras do forno conseguindo estabilização na queima e nas dosagens de emulsão nos queimadores.

Para garantir uma boa operação nas câmaras e no forno foi necessário definir premissas para as rotinas de operação, sendo que as principais estão listadas abaixo:

> Manter do perfil térmico do forno e especial os limites de especificação de temperatura do andar 14 do forno

$>$ Manter a distribuição de ar de topo nos fornos

> Padronização do fator "N" (faixa estequiometria) e fator "K" (quantidade de ar) das câmaras de combustão, em função do perfil térmico do forno e temperatura das câmaras de combustão, menor que $1390^{\circ} \mathrm{C}$.

> Criação de novo padrão de trabalho para operação do sistema de mistura dos combustíveis e combustão do mesmo.

$>$ Acompanhamento diário em reuniões, das principais variáveis do processo

$>$ Treinamento dos operadores de painel e operadores de área

> Um operador painel e um operador de campo exclusivo para o sistema de queima de emulsão

> Manter a composição do gás redutor $(\mathrm{CO}+\mathrm{H} 2)$ em torno de $22 \%$ na câmara de combustão.

\section{RESULTADOS E DISCUSSÃO}

O projeto de queima de emulsão de óleo $2 \mathrm{~A} / 1 \mathrm{~A}$ + Coque no forno $\mathrm{H}$ se mostrou inovador uma vez que a queima desta mistura em câmara de combustão em fornos tipo Nichols Herreshof é o primeiro no mundo.

A idéia surgiu da possibilidade da otimização na utilização dos ativos, usando a capacidade ociosa da estação de emulsão de óleo + coque. Houve desenvolvimento da equipe pautada pelas práticas e crenças Votorantim, com destaque para excelência, aliança e senso de dono. A taxa de substituição óleo por coque nos

* Contribuição técnica ao $35^{\circ}$ Seminário de Balanços Energéticos Globais e Utilidades e $29^{\circ}$ Encontro de Produtores e Consumidores de Gases Industriais, 13 a 15 de agosto de 2014, São Paulo, SP, Brasil. 


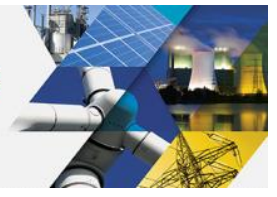

fornos aumentou em 2013 pela adaptação de duas câmaras no final de dezembro (2012) e meados de janeiro no Forno I (Câmaras 07I e 09I respectivamente). Com o sucesso dos testes e com investimento de aproximadamente 140 mil reais em tubulações e válvulas foi possível construir uma linha de dosagem para todas as câmaras do forno H. Com isso atingimos a taxa global de substituição de 12,99\% (ver figura 6). Em dezembro de 2013 foram adaptadas mais duas câmaras do forno I (08I e 10l) restando apenas 6 câmaras para obter mais um forno com $100 \%$ da matriz sendo emulsão de óleo+coque. A previsão para a adaptação das demais 6 câmaras é Junho de 2014.

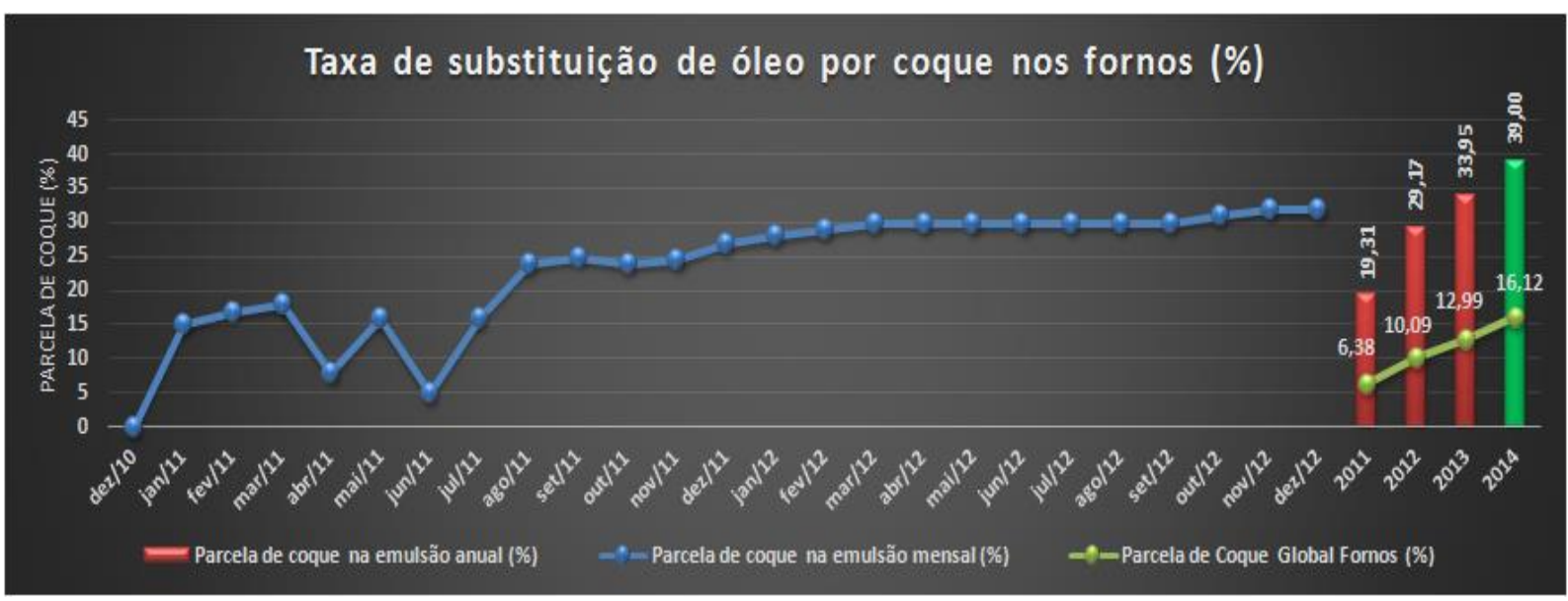

Figura 6 - Evolução da taxa de substituição Global ao longo dos anos e acumulado até abril de 2014. Fonte: Banco de dados "teclink"

A implantação deste projeto trouxe em 2013 um ganho com a redução de custo na ordem de $R \$ 292.584,00$ (ver tabela 1 ) considerando preço médio de óleo A2 praticado em 2013 e desempenho realizado no período de implantação do projeto (Ago /13 à Dez/14). Para 2014 projeta-se um ganho de aproximadamente 1,7 milhões de reais.

Tabela 1- Preços dos combustíveis

\begin{tabular}{c|c|c|c|} 
Ano & Preço Óleo A2 (RS/t) & Preço Óleo Al (RS/t) & Preço do Coque de Petróleo (RS/t) \\
\hline Base 2013 & $1.223,23$ & - & 671,12 \\
\hline Base 2014 & - & $1.399,30$ & 665,38 \\
\hline
\end{tabular}

Fonte: Controladoria Votorantim Metais.

Observação: preços sem ICMS.

\section{CONCLUSÃO}

O trabalho descrito novamente reforça que a motivação dos profissionais consegue superar expectativas uma vez que é quebrado o paradigma no qual projetos inovadores como este necessitam de grandes investimentos. Através da otimização de ativos existentes, investimento mínimo e com auxílio de ferramentas de gestão, em três anos foi possível praticamente triplicar um dos indicadores que mais impacta no custo de produção dos Fornos de Redução da Unidade Niquelândia da Votorantim Metais. O trabalho permitiu concluir que é possível utilizar combustíveis líquidos como forma de aceleração do processo de queima de combustíveis sólidos. A mistura em forma de emulsão, além de facilitar a dosagem até os queimadores,

* Contribuição técnica ao $35^{\circ}$ Seminário de Balanços Energéticos Globais e Utilidades e $29^{\circ}$ Encontro de Produtores e Consumidores de Gases Industriais, 13 a 15 de agosto de 2014, São Paulo, SP, Brasil. 
otimiza a gaseificação do sólido uma vez que a combustão inicial do óleo em contato direto com coque promove a geração da energia de ativação necessária para o processo. Mesmo sendo um processo de queima redutora, ou seja, utilizando quantidades subestequeométricas de ar, o processo se mostrou viável operacionalmente tendo em vista que os parâmetros de processo não foram prejudicados.

\section{Agradecimentos}

Em nome da equipe executora fica os agradecimentos a toda a equipe de Operação e Manutenção da UGB - Via Seca que com muito trabalho, persistência, vontade, conhecimento técnico e principalmente com muita segurança ao planejar e executar as atividades, foi possível alcançar os resultados. Agradecimentos também à Equipe de Tecnologia Corporativa por apoiar, acreditar e suprir os recursos necessários para execução do trabalho.

\section{BIBLIOGRAFIA}

1 Cavalcante PA, et al. Combustão de emulsão de óleo 2 A mais coque de petróleo em câmaras de combustão. 16ํㅜㄹêmio de Excelência da Indústria Mínero-Metalúrgica Brasileira (Energia). Minérios e Minerales; 2014.

2 Ushima AH. Combustão de Sólidos. [Curso de Combustão Industrial]. Instituto de Pesquisas Tecnológicas - IPT; 2013.

3 Sousa FDA. Combustão de Líquidos [Curso de Combustão Industrial]. Instituito de Pesquisas Tecnológicas - IPT; 2013.

\footnotetext{
* Contribuição técnica ao $35^{\circ}$ Seminário de Balanços Energéticos Globais e Utilidades e $29^{\circ}$ Encontro de Produtores e Consumidores de Gases Industriais, 13 a 15 de agosto de 2014, São Paulo, SP, Brasil.
} 